\title{
What Do High-Risk Patients Value? Perspectives on a Care Management Program
}

\author{
Ishani Ganguli, MD, MPH ${ }^{1,2}$, E. John Orav, $P h D^{1,2,3}$, Eric Weil, MD ${ }^{2,4}$, Timothy G. Ferris, $M D, M P H^{2,4}$, and \\ Christine Vogeli, $\mathrm{PhD}^{2,4}$
}

'Brigham and Women's Hospital, Boston, MA, USA; ${ }^{2}$ Harvard Medical School, Boston, MA, USA; ${ }^{3}$ Harvard T.H. Chan School of Public Health, Boston, MA, USA; ${ }^{4}$ Massachusetts General Hospital, Boston, MA, USA.

BACKGROUND: There is growing interest in coordinating care for high-risk patients through care management programs despite inconsistent results on cost reduction. Early evidence suggests patient-centered benefits, but we know little about how participants engage with the programs and what aspects they value.

OBJECTIVE: To explore care management program participants' awareness and perceived utility of program offerings.

DESIGN: Cross-sectional telephone survey administered December 2015-January 2016.

PARTICIPANTS: Patients enrolled in a Boston-area primary care-based care management program.

MAIN MEASURES: Our main outcome was the number of topics in which patients reported having "very helpful" interactions with their care team in the past year. We analyzed awareness of one's care manager as an intermediate outcome, and then as a primary predictor of the main outcome, along with patient demographics, years in the program, attitudes, and worries as secondary predictors.

KEY RESULTS: The survey response rate was $45.8 \%$ ( $n=1220)$; non-respondents were similar to respondents. More respondents reported worrying about family (72.8\%) or financial issues (52.5\%) than about their own health (41.6\%). Seventy-four percent reported care manager awareness, particularly women (OR 1.33, 95\% CI 1.011.77) and those with more years in the program (OR 1.16, 95\% CI 1.03-1.30). While interaction rates ranged from $19.8 \%$ to $72.4 \%$ across topics, $81.3 \%$ rated at least one interaction as very helpful. Those who were aware of their care manager reported very helpful interactions on more topics (OR 2.77, 95\% CI 2.15-3.56), as did women (OR 1.25, 95\% CI 1.00-1.55), younger respondents (OR 0.98 for older age, 95\% CI 0.97-0.99), and those with higher risk scores (OR 1.04, 95\% CI 1.02-1.06), preference for deferring treatment decisions to doctors (OR 2.00, 95\% CI 1.60-2.50), and reported control over their health (OR 1.67, 95\% CI 1.33-2.10).

CONCLUSIONS: High-risk patients reported helpful interactions with their care team around medical and social determinants of health, particularly those who knew their

Received April 5, 2017

Revised August 10, 2017

Accepted September 22, 2017

Published online October 5, 2017 care manager. Promoting care manager awareness may help participants make better use of the program.

KEY WORDS: high-risk care management; high cost patients; patientcentered care; population health management.

$\mathrm{J}$ Gen Intern Med 33(1):26-33

DOI: $10.1007 /$ s11606-017-4200-1

(C) Society of General Internal Medicine 2017

\section{INTRODUCTION}

As provider organizations take on greater financial risk for patients under value-based payment contracts, there is growing focus on the highest risk patients who incur an outsized portion of health care costs. Care management programs have emerged as one strategy to reduce health care costs and utilization for these patients - in particular, through practice-based programs in which care managers embedded in primary care or other clinical sites assist panels of high-risk patients in managing their medical conditions and related psychosocial problems. ${ }^{1,2}$ These programs are predicated on trusting relationships between patients and their care teams to help them navigate complex medical and social issues. ${ }^{3,4}$ While the programs have shown variable success at cost reduction, ${ }^{1,5-7}$ there is limited but growing evidence of patient benefits - such as satisfaction, quality of life, and perceived care integration - that are worthwhile and perhaps more realistic outcomes of such efforts. ${ }^{1,8-11}$ By better understanding how patients engage with care management programs and what they value in these interactions-the mechanisms through which programs might improve cost and quality outcomes-we may come closer to achieving both financial and patient-centered goals. ${ }^{12}$

Therefore, we surveyed patients participating in the Partners HealthCare care management program, a primary care-based, delivery system-operated program and one of the few that have demonstrated reduced costs and utilization, ${ }^{8,13-15}$ to understand patient perspectives on high-risk care management. We explored their attitudes about their health and how much they worried about health, financial, and family issues. We then investigated how many of them were able to identify the presence of a care manager and measured the topic and perceived helpfulness of the interactions they reported having 
with their care teams. We hypothesized that patients who identified the presence of a care manager were more likely to report helpful interactions with their care team around medical and social determinants of health.

\section{METHODS}

Telephone-based surveys of patients enrolled in the Partners HealthCare care management program were conducted by an independent survey research firm between December 7, 2015 and January 26, 2016.

Study Population. We used a stratified random sample of adult Medicare Pioneer Accountable Care Organization, Medicaid, and commercial plan beneficiaries under risk contracts who had been enrolled in the program for at least 6 months prior to survey administration. Program enrollees are 18 years old or greater and are chosen using a claims-based algorithm combined with clinician review. ${ }^{16}$

Survey Instrument. The 15-minute survey addressed the respondent's awareness of a care manager; health attitudes; worry about health, family, and financial issues; and recollection and perception of interactions with their care team.

Patient awareness of a care manager was based on a survey item that asked respondents if there was an individual within their primary care practice who met the functional description of this role. This item, which is used as a quality metric within Partners HealthCare, was internally validated in a previous iteration of the survey by asking respondents to name the individual. We measured preference to leave treatment decisions to one's doctors, perception of control over one's own health, and level of worry about issues including health as well as housing, bills, and caring for family members. ${ }^{17} \mathrm{We}$ used open-ended responses from the previous survey to delineate eight topics of interactions that patients might value having with their care team (Fig. 2). The wording for two of these items was adapted from Massachusetts Health Quality Partners (MHQP) and Consumer Assessment of Healthcare Providers and Systems (CAHPS) surveys. For each item, the respondent was asked if anyone in his/her primary care doctor's office had done the stated task. If the answer was yes, he/ she was asked how helpful it was. If the answer was no, he/she was asked how helpful it might be.

Survey Distribution. We called 3936 potential respondents between December 7, 2015 and January 26, 2016. Six call attempts were made for each individual to maximize sample size. Surveys were conducted in English and in Spanish.

Measures. We determined baseline characteristics including the 2016 Impact Pro Risk Score (calculated using JanuaryDecember 2015 claims) as well as area-level poverty (percent of individuals living in the subject's census tract with incomes below the federal poverty level, among those for whom data were available) and area-level education (percent of individuals living in the subject's census tract who attended any amount of college, among those for whom data were available) from the 2008-2012 American Community Survey. ${ }^{18}$

We dichotomized each type of worry as present ("a great deal" or "a fair amount") or absent ("only a little" or "not at all"). Caregiver worry was defined as reported worrying about "caring for your family" or "the health of a close family member," while financial worry was defined as reported worrying about "paying your bills," "running out of food or affording food," or "maintaining your income or job." We reported health control (defined as "strongly agree" that "I have control over my health") and, separately, preference for doctors making treatment decisions (defined as "strongly agree" that "I prefer to leave all treatment decisions to my doctors"). Care manager awareness was defined as answering "yes" to the question: "Is there someone who works with your primary care doctor who helps you with your medical care?"

Data Analysis. We calculated descriptive statistics of respondents' demographic and other baseline characteristics; health attitudes; health, financial, and caregiver worries; awareness of their care manager; and the receipt and perceived or anticipated helpfulness of various topics of interactions with the care team. Confidence intervals were calculated using standard error. To evaluate differences between respondents and non-respondents, we used chisquare tests for categorical variables and $\mathrm{t}$-tests for continuous variables.

We first analyzed care manager awareness as an intermediate outcome. We then examined awareness of the care manager as a primary predictor and time in the program, health worry, financial worry, and caregiver worry as secondary predictors of our main outcome: the number of issues about which patients reported having "very helpful" interactions with their care team (range 0-8). For the binary outcome assessing awareness of the care manager, we performed bivariate analyses using the t-test for continuous variables and the chi-square test for dichotomized variables. For the ordinal outcome measuring the number of very helpful interactions, we used univariate ordinal logistic regression models.

Models. We built a logistic regression model to determine the adjusted effects on care manager awareness of sex, age, insurer, risk score, preference to defer health decisions, health control, health, financial, and caregiver worry, and time in the program. We then created an ordinal logistic regression model to examine the effect of care manager awareness on the number of very helpful interaction topics while controlling for gender, age, insurance type, risk score, preference to defer health decisions, health control, health, financial, and caregiver worry, and time in the program. 
Table 1 Respondent and Non-Respondent Characteristics

\begin{tabular}{|c|c|c|c|}
\hline Characteristic & Respondents $(n=1182)$ & Non-respondents $(n=2766)^{\mathrm{a}}$ & P value \\
\hline Female & $60.8 \%(719)^{\mathrm{b}}$ & $61.7 \%(1707)^{\mathrm{b}}$ & 0.43 \\
\hline Age, years $(95 \% \mathrm{CI})$ & $70.7(69.9-71.5)$ & $70.0(69.5-70.6)^{\mathrm{b}}$ & 0.20 \\
\hline Race (Medicare only) & & & 0.06 \\
\hline White & $89.8 \%(696)^{\mathrm{c}}$ & $88.3 \%(1498)$ & \\
\hline Black & $7.4 \%(57)$ & $6.8 \%(116)$ & \\
\hline Other & $2.8 \%\left({ }^{22}\right)$ & $4.9 \%(83)^{\mathrm{d}}$ & \\
\hline Area-level poverty, mean \% below federal poverty level (95\% CI) & $9.5 \%(8.9-10.0)^{\mathrm{e}}$ & $9.9 \%(9.5-10.3)^{\mathrm{f}}$ & 0.25 \\
\hline Area-level education, mean \% who attended some college $(95 \% \mathrm{CI})$ & $65.8 \%(64.7-66.8)^{\mathrm{e}}$ & $65.2 \%(64.5-65.8)^{\mathrm{f}}$ & 0.32 \\
\hline Insurer & & & 0.02 \\
\hline Medicare ACO & $66.0 \%(780)$ & $61.9 \%(1713)$ & \\
\hline Commercial & $28.2 \%(333)$ & $32.5 \%(898)$ & \\
\hline Medicaid & $5.8 \%(69)$ & $5.0 \%(139)^{\mathrm{d}}$ & \\
\hline Impact Pro Risk Score $(95 \%$ CI) & $7.8(7.4-8.2)^{\mathrm{g}}$ & $7.5(7.3-7.8)^{\mathrm{h}}$ & 0.25 \\
\hline Years in program $(95 \% \mathrm{CI})$ & $2.5(2.4-2.6)$ & $3.0(2.7-3.2)^{\mathrm{i}}$ & 0.04 \\
\hline Reported awareness of care manager & $73.7 \%(871)$ & $\mathrm{N} / \mathrm{A}$ & \\
\hline Preference to defer decisions to doctors & $39.3 \%(464)$ & $\mathrm{N} / \mathrm{A}$ & \\
\hline Health control & $64.2 \%(749)^{\mathrm{d}}$ & $\mathrm{N} / \mathrm{A}$ & \\
\hline Health worry & $41.6 \%(492)$ & $\mathrm{N} / \mathrm{A}$ & \\
\hline Caregiver worry & $72.8 \%(861)$ & $\mathrm{N} / \mathrm{A}$ & \\
\hline Financial worry & $52.5 \%(621)$ & N/A & \\
\hline
\end{tabular}

95\% CI, 95\% confidence interval; bold if statistically significant

$A C O$, accountable care organization. ${ }^{a}$ Some non-respondents were excluded from the response rate calculation based on AAPOR's RR 3 criteria. The nonrespondent analysis includes 50 individuals who were removed from the sample for administrative reasons. Missing data $b: 9, c: 5, d: 16, e: 108, f$ : 274, g: 90, h: 361, $i: 11$

All analyses were performed using STATA 13.0 for Windows (STATA Corp., College Station, TX). All reported $p$ values are two-tailed, and $p<0.05$ was considered statistically significant. The primary purpose of the Partners HealthCare care management program patient survey was to improve care quality; secondary research use of the data was approved by the Partners Institutional Review Board. The study had no external funding source.

\section{RESULTS}

We achieved a $45.8 \%$ response rate based on the American Association for Public Opinion Research RR3 definition $(n=1220){ }^{19} 38$ patients who were discharged from the program prior to the beginning of the survey period were subsequently excluded from this analysis $(n=1182)$. Nonrespondents did not differ significantly from respondents by sex, age, race, area-level poverty and education, or risk score (Table 1). Eight percent of analyzed surveys were completed by proxies $(94,8.0 \%)$.

Demographics, Attitudes, and Worries. Respondents were predominantly female, white, and enrolled in Medicare (Table 1). Their ages ranged from 25 to 104 years old. Over one-third $(39.3 \%)$ of respondents said that they prefer to leave all treatment decisions to their doctors, while $64.2 \%$ reported feeling in control of their health. More respondents reported worrying about a family member's health or taking care of family $(72.8 \%)$ or about financial issues such as bills, maintaining income, or affording food $(52.5 \%)$ than about their own health
(41.6\%). No respondents reported worrying exclusively about their own health (Fig. 1).

Care Manager Awareness. Nearly three quarters (73.7\%) of patients reported someone fitting the description of a care manager (Table 2). Women $(1.33$; 95\% CI 1.01$1.75)$ and those with more time in the program (1.16 per year; 95\% CI 1.03-1.30) had higher odds of identifying a care manager in adjusted analyses. In bivariate analyses, those who reported health and caregiver worry also had higher odds of identifying a care manager, but these effects were not significant in the multivariable model.

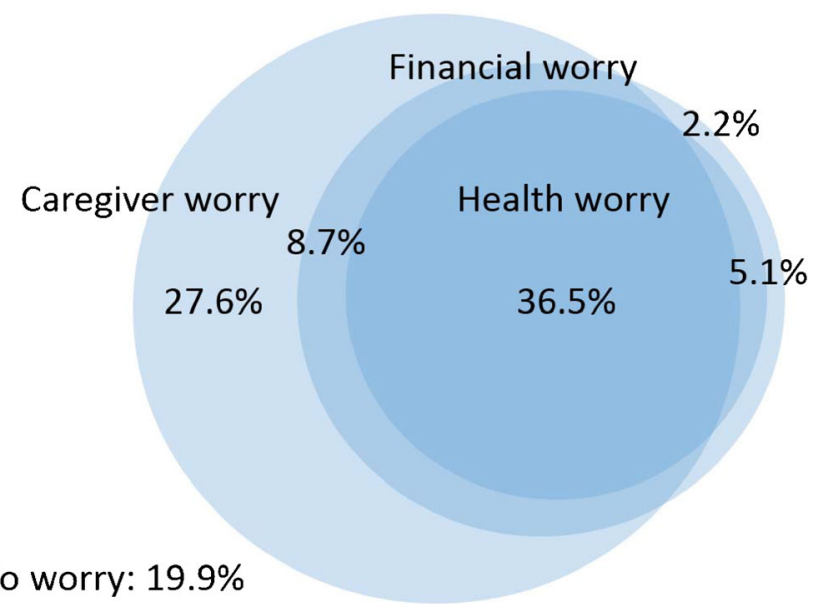

Fig. 1 Patient report of health, caregiver, and financial worry. Venn diagram shows patient report of health worry, financial worry (paying bills, affording food, or maintaining income), and caregiver worry (caring for family or family member's health) 
Table 2 Patient Characteristics Associated with Reported Awareness of Care Manager

\begin{tabular}{|c|c|c|c|c|}
\hline \multirow[t]{2}{*}{ Patient characteristic } & \multicolumn{2}{|c|}{ Awareness of care manager } & \multirow[t]{2}{*}{ Unadjusted OR (95\% CI) } & \multirow[t]{2}{*}{ Adjusted OR (95\% CI) } \\
\hline & Yes $(n=871)$ & No/Do not know $(n=311)$ & & \\
\hline Female & $62.0 \%(540)$ & $57.6 \%(179)$ & $1.20(0.93-1.56)$ & $1.33(1.01-1.77)$ \\
\hline Male & $38.0 \%(331)$ & $42.4 \%(132)$ & Ref & Ref \\
\hline Age, years $(95 \%$ CI) & $70.3(69.5-71.2)$ & $71.7(70.2-73.3)$ & $0.99(0.98-1.00)$ & $1.00(0.99-1.02)$ \\
\hline \multicolumn{5}{|l|}{ Insurer } \\
\hline Medicare & $64.8 \%(564)$ & $69.5 \%(216)$ & Ref & Ref \\
\hline Commercial & $28.7 \%(250)$ & $26.7 \%(83)$ & $1.15(0.86-1.55)$ & $1.30(0.88-1.91)$ \\
\hline Medicaid & $6.5 \%(57)$ & $3.9 \%\left({ }^{12}\right)$ & $1.82(0.96-3.46)$ & $1.97(0.91-4.25)$ \\
\hline Impact Pro Risk Score $(95 \%$ CI) & $7.9(7.4-8.3)$ & $7.5(6.8-8.3)$ & $1.01(0.99-1.03)$ & $1.01(0.99-1.04)$ \\
\hline Years in program $(95 \% \mathrm{CI})$ & $2.5(2.5-2.6)$ & $2.4(2.2-2.5)$ & $1.12(1.01-1.25)$ & $1.16(1.03-1.30)$ \\
\hline Preference to defer decisions & $40.4 \%(352)$ & $36.01 \%(112)$ & $1.21(0.92-1.58)$ & $1.31(0.97-1.75)$ \\
\hline Health control & $64.77 \%(557)$ & $62.75 \%(192)$ & $1.09(0.83-1.43)$ & $1.05(0.79-1.41)$ \\
\hline Health worry & $43.6 \%(380)$ & $36.0 \%(112)$ & $1.38(1.05-1.80)$ & $1.47(0.93-2.33)$ \\
\hline Caregiver worry & $74.5 \%(649)$ & $68.2 \%(212)$ & $1.37(1.03-1.81)$ & $1.26(0.92-1.74)$ \\
\hline Financial worry & $54.1 \%(471)$ & $48.2 \%(150)$ & $1.26(0.98-1.64)$ & $0.85(0.54-1.33)$ \\
\hline
\end{tabular}

OR, odds ratio; 95\% CI, 95\% confidence interval. Bold if statistically significant

We built a regression model with the following covariates: sex, age, insurer, risk score, years in program, decision-making preference, health control, and health, caregiver, and financial worry

Interactions with Care Team. The percentage of respondents reporting a given topic of interaction in the previous year ranged from $19.8 \%$ to $72.4 \%$ (Fig. 2). Eighty-one percent $(81.3 \%)$ reported at least one topic of "very helpful" interaction with their care team; respondents reported such interactions on an average of three out of eight possible topics. Patients who identified the presence of a care manager were more likely to recall interactions in each of the topics (data not shown) and had significantly greater odds $(2.77 ; 95 \% \mathrm{CI}$ 2.15-3.56) of reporting very helpful interactions across more topics when controlling for covariates (Table 3). Women, younger patients, and respondents with higher risk score as well as those who reported health control and preference to defer treatment decisions also had greater odds of reporting more of these interactions. In bivariate analysis, Medicaid patients had greater odds of reporting very helpful interactions, but this result was no longer significant in the multivariate model. In a secondary analysis, we found that this effect was explained by younger age and higher odds of financial and health worry among Medicaid patients compared to Medicare beneficiaries.

\section{DISCUSSION}

We found that patients in a high-risk care management program reported very helpful interactions with their care team around core program features such as post-hospitalization follow-up and addressing barriers to self-care, although there were some missed opportunities for engagement. Those who were aware of their care manager were more likely to report very helpful interactions with the care team across more topics.

Program participants were enrolled primarily on the basis of their medical cost and complexity, yet notably, no respondent worried exclusively about their own health and they were more likely to report worrying about family members or about financial issues. These findings substantiate previous studies showing that high cost patients tend to have greater unmet resource needs ${ }^{20}$ and lower socioeconomic status. ${ }^{21-25}$ These challenges, in turn, may make it more difficult for individuals to address health issues or navigate the health system. ${ }^{17,20,26-28}$ Responses to questions about worry may not only reflect health and socioeconomic realities but also the respondents' propensity to worry, a trait that seems to be independent of anxiety and depression. ${ }^{29}$ Whatever the underlying cause, the marked prevalence of these worries emphasizes the need for care management programs to help patients address such issues. These findings also highlight the idea that patients' priorities may not align with those perceived or focused on by their clinicians and that collaborative goal setting with patients may be an important strategy to improve outcomes. ${ }^{27}$

Awareness of the Care Manager. Most respondents reported that there was "someone who works with your primary care doctor who helps you with your medical care"-suggesting that they could identify the individual and found his or her role helpful. This question serves as an institution-wide quality metric - a marker of the relationship upon which the program is based - and the proportion responding yes rose by $10 \%$ from the previous year. In our survey, participants enrolled in the program for longer durations were more likely to answer "yes," perhaps reflecting greater opportunity to become acquainted with their care managers; women were also more likely to identify a care manager.

Interactions. Previous work has found that patients in care management programs are 1.3 to 2.6 times more likely than non-enrollees to recall receiving education on topics such as diet, exercise, and medication administration; in most of the programs studied, the majority of participants recalled having such discussions and receiving help from their care teams, but it was not clear if they found them helpful. ${ }^{5}$ In our study, most 
Yes, very helpful

Yes, somewhat or not at all helpful

No, would be very helpful

No, would be somewhat or not at all helpful

a. Talk with you about your medications including side-effects and when to take your medications

b. Talk with you about your family, home life or living situation

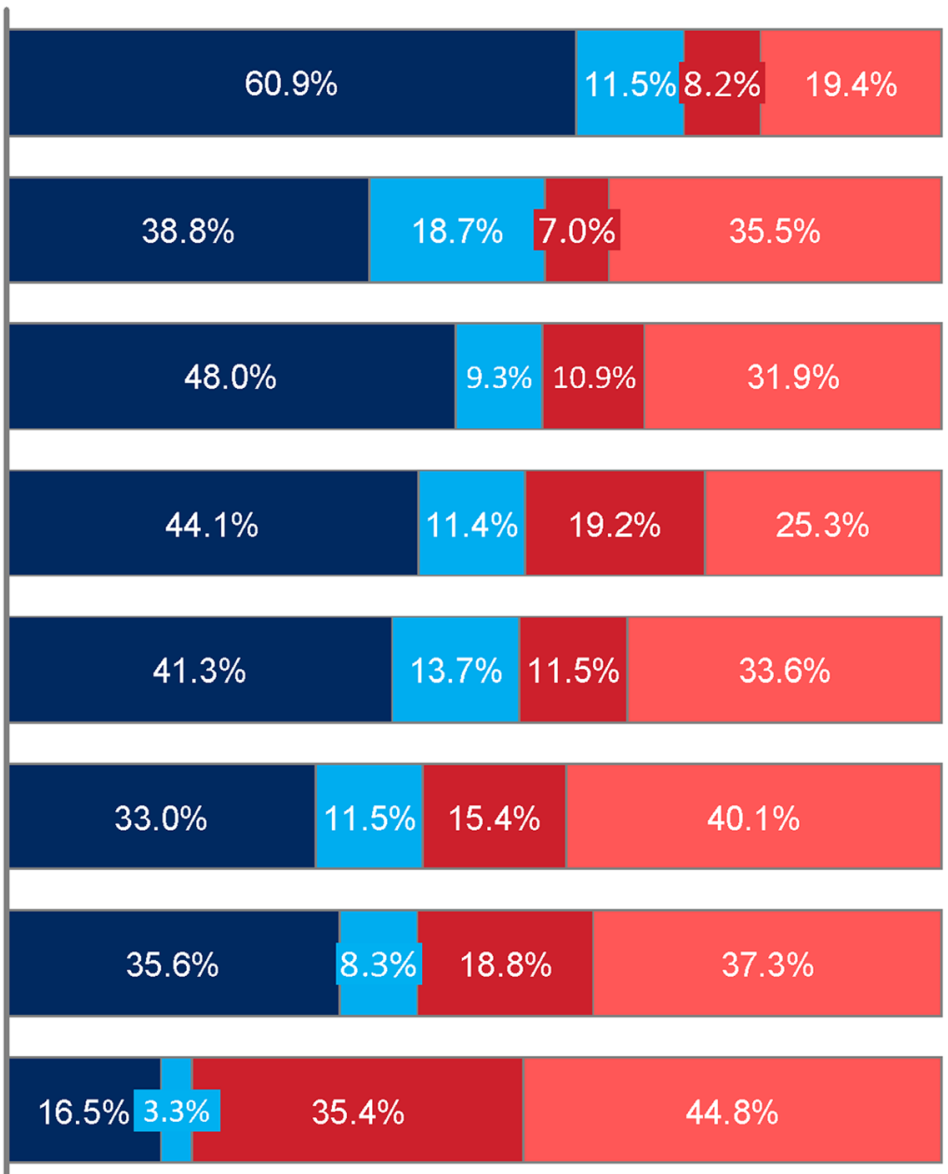

d. Call you after you visited an emergency room or came home after a hospital stay

e. Talk with you about things in your life that worry you or cause you stress*

f. Ask you if there are things that make it hard for you to take care of your health*

g. Talk with you about your wishes and preferences for care if you were to get sicker

h. Talk with you about getting free / reduced cost medications or medical supplies

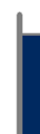

$48.0 \%$

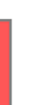


Table 3 Effects of Patient Characteristics on Number of Reported "Very Helpful" Interactions

\begin{tabular}{|c|c|c|}
\hline Characteristic & $\begin{array}{l}\text { Unadjusted OR } \\
(95 \% \mathrm{CI})\end{array}$ & $\begin{array}{l}\text { Adjusted OR } \\
(95 \% \mathrm{CI})\end{array}$ \\
\hline Female & $1.18(0.96-1.45)$ & $1.25(1.00-1.55)$ \\
\hline Age & $0.98(0.97-0.99)$ & $0.98(0.97-0.99)$ \\
\hline \multicolumn{3}{|l|}{ Insurer } \\
\hline Medicare & Ref & Ref \\
\hline Commercial & $1.24(0.99-1.55)$ & $1.03(0.76-1.39)$ \\
\hline Medicaid & $2.09(1.33-3.27)$ & $1.28(0.74-2.21)$ \\
\hline Mean Impact Pro Risk & $1.04(1.02-1.05)$ & $1.04(1.02-1.06)$ \\
\hline Score & & \\
\hline Years in program & $1.08(1.00-1.17)$ & $1.09(1.00-1.19)$ \\
\hline $\begin{array}{l}\text { Preference to defer } \\
\text { decisions }\end{array}$ & $1.85(1.51-2.28)$ & $2.00(1.60-2.50)$ \\
\hline Health control & $1.69(1.37-2.08)$ & $1.67(1.33-2.10)$ \\
\hline Health worry & $1.59(1.30-1.95)$ & $1.34(0.94-1.91)$ \\
\hline Caregiver worry & $1.43(1.14-1.80)$ & $1.17(0.91-1.51)$ \\
\hline Financial worry & $1.52(1.24-1.86)$ & $0.94(0.66-1.34)$ \\
\hline $\begin{array}{l}\text { Reported awareness of } \\
\text { care manager }\end{array}$ & $3.07(2.43-3.88)$ & $2.77(2.15-3.56)$ \\
\hline
\end{tabular}

OR, odds ratio; $95 \%$ CI, 95\% confidence interval. Bold if statistically significant

We built a regression model with reported awareness of the care manager as the primary predictor and the following covariates: sex, age, insurer, risk score, years in program, decision-making preference, health control, and health, caregiver, and financial worry

health care services than men, including more medical visits, and report higher satisfaction with care. ${ }^{31,32}$ This may also reflect the positive impact of gender concordance in building relationships, given that approximately $95 \%$ of care managers in the Partners program are female. Younger patients and those with greater medical complexity were also more likely to report very helpful interactions across topics, perhaps reflecting greater need for these services. We also found that patients who reported control over their health as well as those who preferred to leave treatment decisions to their doctors had higher odds of reporting very helpful interactions across more topics. These associations might be mediated by factors such patients' ability to express and advocate for their needs during an interaction or by patients' trust in their doctors or in the health system. Interestingly, a previous study found that hospitalized patients who preferred to defer medical decisions had shorter lengths of stay and lower hospitalization costs. ${ }^{33}$

Finally, while our study was underpowered with respect to Medicaid enrollment, these patients were disproportionately likely to know their care manager and, in bivariate analysis, had statistically significant greater odds of reporting more helpful interactions, suggesting that these patients may particularly benefit from care management. This is particularly notable given the recent emergence of Medicaid Accountable Care Organization pilot programs in Massachusetts and elsewhere.

Implications. Though it is impossible to show causality in this study design, the association between care manager awareness and the number of very helpful interactions does support the hypothesis that an intervention that strengthens patients' relationships with their care manager may help them make better use of the program. This finding is consistent with previous studies showing that successful care management programs are more likely to feature frequent face-to-face interactions between care managers and patients. ${ }^{6}$ An intervention such as an introductory video series might similarly help patients get to know their care managers and has since been employed at some program sites. ${ }^{34}$ In addition, our study suggests that patient attributes such as preference to defer treatment decisions or sense of health control may help to identify candidates who will most benefit from these resource-intensive programs. ${ }^{3}$

Limitations. These results should be interpreted in the context of the study's limitations. The survey focused on the care management program of a single health system, albeit one that represents one of a few successful care management models and spans several care settings including two quarternary care hospitals and numerous community-based primary care sites and community health centers. ${ }^{8,13,15}$ Our response rate was somewhat low, though not unusually so for a patient survey in a high-risk population. ${ }^{35}$ Furthermore, we found nonsignificant differences between respondents and non-respondents across most demographic categories, suggesting limited non-response bias. ${ }^{36}$ Respondents were more likely than non-respondents to be Medicare beneficiaries and to have spent less time in the program, so our findings may disproportionately represent these groups.

Due to the cross-sectional design, we cannot make causal inferences about the associations that we observed. We assumed stability of responses about worries and health attitudes, though some aspects of worry such as food security may be dynamic in the course of a year. We used generic terminology to ask respondents if they were aware of their care manager because this role has differing titles across care management program sites; this may have biased our estimates in either direction. Respondents may have difficulty remembering interactions over the past year, so we may underestimate interaction rates; however, at most $5.4 \%$ of respondents answered "I do not know" to any of these questions. Finally, the hybrid claims and clinician-based patient selection methodology used in the Partners HealthCare care management program may skew our sample in favor of patients who are perceived as either engaged or having needs likely to be met by the program, ${ }^{16}$ limiting the generalizability of our study to programs with a similar selection approach. However, to our knowledge, most programs employ this approach, mitigating this limitation. ${ }^{37}$

Despite these limitations, this study robustly addresses the patient-centered outcomes of care management interventions that may serve as more proximal and meaningful outcomes of such programs than reductions in cost and utilization.

Conclusion. We found that respondents worried much more about financial and caregiver issues than about 
their own health, reinforcing the socioeconomic burdens felt by high-risk patients and the need for programs to address these issues. As with any intervention, it is important to ensure that care management programs provide patients with services that they themselves want and find to be useful. Most participants in our survey found interactions with the care team very helpful across several topics, particularly if they were aware of their care managers, suggesting that strengthening these relationships may improve the patient-centered outcomes that are meaningful and realistic goals of high-risk care management.

Corresponding Author: Ishani Ganguli, MD, MPH; Brigham and Women's Hospital, Boston, MA, USA (e-mail: iganguli@bwh.harvard. edu).

Contributors: We thank Maryann Vienneau (Partners Center for Population Health) and Jessica Moschella, MPH (Emerson PhysicianHospital Organization) for their work on the Partners HealthCare care management program and Tom Bodenheimer, MD, MPH (University of California, San Francisco), for his thoughtful review of our manuscript.

Funding: There was no financial or material support for the design and conduct of the study; collection, management, analysis, and interpretation of the data; and preparation, review, or approval of the manuscript.

\section{Compliance with ethical standards:}

Prior presentations: This work was presented at the 2017 Society of General Internal Medicine Annual Meeting on April 21, 2017.

Conflict of interest statement: The authors declare no conflicts of interest.

\section{REFERENCES}

1. Berry-Millett R, Bodenheimer TS. Care management of patients with complex health care needs. Synth Proj Res Synth Rep.

2. Bodenheimer T, Berry-Millett R. Follow the money-controlling expenditures by improving care for patients needing costly services. N Engl J Med. 2009;361:1521-3.

3. Colbert J, Ganguli I. To Identify Patients For Care Management Interventions, Look Beyond Big Data. Health Affairs Blog. April 19, 2016. http://healthaffairs.org/blog/2016/04/19/to-identify-patientsfor-care-management-interventions-look-beyond-big-data/. Accessed April 4, 2017.

4. Nelson L. Lessons From Medicare's Demonstration Projects on Disease Management and Care Coordination. Washington, DC: Congressional Budget Office; 2012. Working paper 2012-01.

5. Peikes D, Chen A, Schore J, Brown R. Effects of care coordination on hospitalization, quality of care, and health care expenditures among Medicare beneficiaries: 15 randomized trials. JAMA. 2009;301:603-18.

6. Brown RS, Peikes D, Peterson G, Schore J, Razafindrakoto CM. Six features of Medicare coordinated care demonstration programs that cut hospital admissions of high-risk patients. Health Aff (Millwood). 2012;31:1156-66.

7. Zulman DM, Cee CP, Ezeji-Okoye SC, et al. Effect of an intensive outpatient program to augment primary care for high-need Veterans Affairs patients: a randomized clinical trial. JAMA Intern Med. 2017; $177: 166-175$

8. McCall N, Cromwell J, Urato C. Evaluation of Medicare Care Management for High Cost Beneficiaries (CMHCB) Demonstration:
Massachusetts General Hospital and Massachusetts General Physicians Organization (MGH). 2010. http://www.cms.gov/Research-StatisticsData-and-Systems/Statistics-Trends-and-Reports/Reports/downloads/ mccall_mgh_cmhcb_final_2010.pdf. Accessed November 14, 2016.

9. McWilliams JM, Landon BE, Chernew ME, Zaslavsky AM. Changes in patients' experiences in Medicare accountable care organizations. N Engl J Med. 2014; 371:1715-1724.

10. McWilliams JM. Cost containment and the tale of care coordination. N Engl J Med. 2016; 375:2218-2220.

11. Fryer AK, Friedberg MW, Thompson RW, Singer SJ. Achieving care integration from the patients' perspective: results from a care management program. Healthc (Amst). 2016;4:36-44.

12. Ganguli I, Thompson RT, Ferris TG. What can five high cost patients teach us about healthcare spending? Healthe (Amst). 2016. https://doi. org/10.1016/j.hjdsi.2016.12.004.

13. Urato C, McCall N, Cromwell J, Lenfestey N, Smith K, and Raeder, D. Evaluation of the Extended Medicare Care Management for High Cost Beneficiaries (CMHCB) demonstration: Massachusetts General Hospital (MGH). Final report. Research Triangle Park, NC: RTI International. 2013.

14. Hong CS, Siegel AL, Ferris TG. Caring for High-Need, High-Cost Patients: What Makes for a Successful Care Management Program? The Commonwealth Fund, August 2014.

15. Hsu J, Price M, Vogeli C, Chernew M, Ferris TG. The impact of new payment models on care delivery: reductions in emergency care use among beneficiaries in a Medicare Pioneer ACO. Int $J$ Qual Health Care. 2016;28(suppl 1).

16. Vogeli C, Spirt J, Brand R, Hsu J, Mohta N, Hong C, Weil E, Ferris TG. Implementing a hybrid approach to select patients for care management: variations across practices. Am J Manag Care. 2016;22:358-65.

17. Gelberg L, Gallagher TC, Andersen RM, Koegel P. Competing priorities as a barrier to medical care among homeless adults in Los Angeles. Am J Public Health. 1997;87:217-220.

18. American Community Survey. https://www.census.gov/programs-surveys/acs/data.html. Accessed April 4, 2017.

19. The American Association for Public Opinion Research. Standard Definitions: Final Dispositions of Case Codes and Outcome Rates for Surveys. April 2015. https://www.aapor.org/AAPOR_Main/media/publications/Standard-Definitions2015_8theditionwithchanges_April2015_ logo.pdf. Accessed January 23, 2017.

20. Berkowitz SA, Hulberg AC, Hong C, Stowell BJ, Tirozzi KJ, Traore CY, Atlas SJ. Addressing basic resource needs to improve primary care quality: a community collaboration programme. BMJ Qual Saf. 2016;25:164-72.

21. Hunt KA, Weber EJ, Showstack JA, Colby DC, Callaham ML. Characteristics of frequent users of emergency departments. Ann Emerg Med. 2006;48:1-8.

22. Sutherland JM, Fisher ES, Skinner JS. Getting past denial-the high cost of health care in the United States. N Engl J Med. 2009;361:1227-1330.

23. Health Policy Commission. 2013 Cost Trends Report. Boston, MA. 2013 http://www.mass.gov/anf/docs/hpc/2013-cost-trends-report-full-report.pdf. Accessed April 4, 2017.

24. Johnson TL, Rinehart DJ, Durfee $\mathbf{J}$ et al. For many patients who use large amounts of health care services, the need is intense yet temporary. Health Aff (Millwood). 2015;34:1312-9.

25. Ryan J, Abrams MK, Doty MM, Shah T, Schneider EC. How High-Need Patients Experience Health Care in the United States: Findings from the 2016 Commonwealth Fund Survey of High-Need Patients, The Commonwealth Fund, December 2016.

26. Schlossstein E, St. Clair P, Connell F. Referral keeping in homeless women. J Community Health. 1991;16:279-285.

27. Zulman DM, Kerr EA, Hofer TP, Heisler M, Zikmund-Fisher BJ. Patient-provider concordance in the prioritization of health conditions among hypertensive diabetes patients. J Gen Intern Med. 2010;208-414.

28. Mautner DB, Pang H, Brenner JC, Shea JA, Gross KS, Frasso R, Cannuscio CC. Generating hypotheses about care needs of high utilizers: lessons from patient interviews. Popul Health Manag. 2013;16 Suppl 1:S26-33.

29. Meyer TJ, Miller ML, Metzger RL, Borkovec TD. Development and validation of the Penn State worry questionnaire. Behav Res Ther. 1990;28:487-95.

30. Berkowitz SA, Hulberg AC, Standish S et al. Addressing unmet basic resource needs as part of chronic cardiometabolic disease management. JAMA Intern Med. 2017;177:244-252.

31. Bertakis KD, Azari R, Helms LJ, Callahan EJ, Robbins JA. Gender differences in the utilization of health care services. J Fam Pract. 2000;49:147-52. 
32. Bertakis KD. The influence of gender on the doctor-patient interaction. Patient Educ Couns. 2009;76:356-60.

33. Tak HJ, Ruhnke GW, Meltzer DO. Association of patient preferences for participation in decision making with length of stay and costs among hospitalized patients. JAMA Intern Med. 2013; 173:1195-1205.

34. Ganguli I, Sikora C, Nestor B, et al. A scalable program for customized patient education videos. Jt Comm J Qual Patient Saf. 2017. https://doi. org/10.1016/j.jcjq.2017.05.009.
35. Elliott MN, Zaslavsky AM, Goldstein E, et al. Effects of survey mode, patient mix, and nonresponse on CAHPS hospital survey scores. Health Serv Res. 2009;44:501-518.

36. Davern M. Nonresponse rates are a problematic indicator of nonresponse bias in survey research. Health Serv Res 2013;48:905-12.

37. Hong CS, Hwang AS, Ferris TG. Finding a Match: How Successful Complex Care Programs Identify Patients. Issue Brief California HealthCare Foundation. http://www.chcf.org/ /media/ M E D I A 20 L I B R R \% 20 Files / P D F / P D F 20 F / PDF\%20FindingMatchComplexCare.pdf. Accessed July 14, 2017. 